IZA DP No. 6978

Gender Gaps in Spain: Family Issues and the Career Development of College Educated Men and Women

Ainara González de San Román

Sara de la Rica

October 2012 


\title{
Gender Gaps in Spain: Family Issues and the Career Development of College Educated Men and Women
}

\author{
Ainara González de San Román \\ $U P V-E H U$ \\ Sara de la Rica \\ UPV-EHU, FEDEA and IZA
}

Discussion Paper No. 6978

October 2012

\author{
IZA \\ P.O. Box 7240 \\ 53072 Bonn \\ Germany \\ Phone: +49-228-3894-0 \\ Fax: +49-228-3894-180 \\ E-mail: iza@iza.org
}

\begin{abstract}
Any opinions expressed here are those of the author(s) and not those of IZA. Research published in this series may include views on policy, but the institute itself takes no institutional policy positions. The IZA research network is committed to the IZA Guiding Principles of Research Integrity.

The Institute for the Study of Labor (IZA) in Bonn is a local and virtual international research center and a place of communication between science, politics and business. IZA is an independent nonprofit organization supported by Deutsche Post Foundation. The center is associated with the University of Bonn and offers a stimulating research environment through its international network, workshops and conferences, data service, project support, research visits and doctoral program. IZA engages in (i) original and internationally competitive research in all fields of labor economics, (ii) development of policy concepts, and (iii) dissemination of research results and concepts to the interested public.
\end{abstract}

IZA Discussion Papers often represent preliminary work and are circulated to encourage discussion. Citation of such a paper should account for its provisional character. A revised version may be available directly from the author. 


\section{ABSTRACT}

\section{Gender Gaps in Spain: Family Issues and the Career Development of College Educated Men and Women*}

Our goal in this paper is to focus on highly educated men and women and try to explore the trade-offs between family and working career in Spain, where changes in female behavior with respect to the labor market have been relatively recent but rather important. We compare male and female behavior with respect to labor supply and labor performance along their life cycle for different birth cohorts to explore the connection between family and work over time. Our results indicate that family plays a crucial role as a source of gender differences in the labor market in Spain. By 2008, children are the main determinant of the observed gap in labor supply between college men and women. Furthermore, with respect to hours worked, children are also an important determinant for the decision of college-educated mothers to choose to work part-time. However, children do not seem to contribute to explain the observed gender wage gap (5\%) between college men and women.

JEL Classification: J12, J2, J3

Keywords: gender gaps, career development, family and work, Spain

Corresponding author:

Sara de la Rica

Departamento de Fundamentos del Análisis Económico II

Universidad del País Vasco

Lehendakari Aguirre 83

48015 Bilbao

Spain

E-mail: sara.delarica@ehu.es

\footnotetext{
Financial support from the Spanish Ministry of Science and Innovation under projects BES-2007-14507 and ECON2009-10818 is gratefully acknowledged.
} 


\section{Introduction}

Among the most important determinants of a countries' competitiveness is its human capital endowment - the skills, education and productivity, that is, of its labor force. Over time, this competitiveness depends very much on how countries use their human resources. The shrinking of the working-age population and the high educational level achieved by women over recent decades ${ }^{1}$ make it essential to consider women as a fundamental part of the workforce. Governments and Institutions may play an important role in creating the legal framework for improving women's education and their participation to the economy, as well as helping societies to break away from the more traditional gender role attitudes that affect women's behavior in many countries. It is also crucial that firms positively believe in the need to create a suitable working environment where men and women can combine work and family.

Needless to say, women have made huge progress in the workplace, especially in the more industrialized countries. In particular, Goldin (2004) refers to the mass arrival of women into the workforce during the seventies as the "quiet revolution". Describing the evolution of women in the labor market during the $20^{\text {th }}$ century in the US, she states that until the 1920s, working women were basically young and single and worked in factories or as domestic servants. From the 1930s onwards many more went to school and got jobs in offices. In the 1950s many married women entered the labor market and got jobs as secretaries, teachers or nurses. By the 1970s, their daughters saw their mothers working and took it for granted that they would also work. And since the end of the 1980s, women are overtaking men in graduating from college. This process, to a greater or lesser degree, has been observed in most industrialized economies.

However, we believe that family issues play a crucial role in understanding the observed gender differences in the labor market. Women must combine employment with home responsibilities to a much larger extent than their male partners. This affects their decisions with respect to their labor supply, it affects their human capital accumulation, and hence their labor-market performance. Several studies try to explore the trade-offs between family and career among similarly educated men and women. Wood, Corcoran, and Courant (1993) find that $40 \%$ of the gender gap among American lawyers is explained by children. More recent work by Goldin and Katz (2010), and Bertrand, Goldin and Katz (2011) point to the differences in the intensive margin as the main determinant of the gender gap in male and female careers through the negative effect of children on women's hours worked. Finally, Molina and Montuenga (2009) confirm the existence of a wage penalty for Spanish working-women with children.

Our goal in this chapter is to focus on highly educated men and women and try to explore the trade-offs between family and working career in Spain, where changes in female behavior with respect to the labor market have been relatively recent but rather important. We compare male and female behavior with respect

\footnotetext{
${ }^{1}$ See Goldin, Katz and Kuziemko (2006) for an exploratory analysis of the catch-up and reversal in the gender gap in university graduation of American college women.
} 
to labor supply and labor performance along their life cycle for different birth cohorts to explore the connection between family and work over time. Furthermore, we compare the impact of children on labor supply decisions and on women's labor market performance in two periods - 1994 and 2008, which encompass a period of substantial changes with respect to the role of women in the labor market. Our results indicate that indeed, family plays a crucial role as a source of gender differences in the labor market in Spain. By 2008, children are the main determinant of the observed gap in labor supply between college men and women. Furthermore, with respect to hours worked, children are also an important determinant for the decision of college-educated mothers to choose to work part-time. However, children do not seem to contribute to explain the observed gender wage gap (5\%) between college men and women.

The chapter is organized as follows: In the next section, we provide descriptive evidence of gender gaps for Spain. We describe, in particular, employment rates and part-time employment rates, and performance in the labor market as proxied by the presence in top positions (managerial occupations) and wages. Section 3 is devoted to estimate and quantify the impact of children on the career development of men and women (employment rates and part-time employment rates) as well as on their performance in the labor market - wages and the presence in top positions. Section 4 suggests some policy implications derived from the results found in section 3. Finally, section 5 concludes summarizing our findings and recommendations.

\section{Descriptive Evidence: Gender Gaps in the Labor Market along the life cycle}

The goal of this section is to describe the extent to which family issues are related to the gender gap in the labor market (labor supply and performance) for highly educated workers. To do so, we show gender gaps in labor supply (employment rates and part-time rates) and labor performance (incidence in top jobs) along the life cycle for different birth cohorts. This allows comparing gender gaps at different ages and in particular, at pre-maternal and post-maternal ages. The fact that gender gaps increase during child bearing ages -between 25 and 40provides a first indication of the importance of family on the professional careers of college-educated women versus those of their male counterparts. Second, by comparing gender gaps along the life cycle for different birth cohorts it is possible to assess the change of such profile over time, as Spanish society is changing 2 .

There are several studies that trace the labor force experiences of different cohorts of college graduates for the U.S focusing on why career and family outcomes changed over time. Goldin (2004), who is closely related to our study, finds that more recent cohorts - those born in the eighties- have been able to combine both career and family whereas the older ones were much more forced to choose between one of the two. We will present next similar evidence for the case of Spain.

\footnotetext{
${ }^{2}$ For space restrictions, we do not report gender gaps on these indicators for all men and women. In general, the gaps are bigger when the whole population is taken into account.
} 


\subsection{Employment Rates along the life cycle}

We use the Spanish Labor Force Surveys since 1986 to construct the Employment Rates as the ratio of individuals who are working at the time of the survey divided by the total population between 25 and 60 years of age. Moreover, in order to assess how these rates evolve for different groups in our sample, we construct this indicator by gender, education group-college/non-college, and for different age intervals. Figure 1 shows life-cycle Employment Rates for college females (y-axis) for seven age groups (x-axis). Each line corresponds to a different birth cohort $^{3}$, and therefore, for each of them it is possible to look at average changes in labor market indicators throughout the life cycle.

Figure 1 shows that for the two earlier cohorts - the one born in 1960 and the one born in 1965, the life cycle profile is different than the corresponding one for later cohort. In particular, the two youngest cohorts have a more apparent concave profile than the oldest ones, with an employment rate continuously increasing even at child-bearing ages. When comparing employment rates of college men and women, significant differences emerge at different stages of the life cycle. Figure 2 presents the relative employment rate of college women with respect to college men.

At very young ages, employment rates for college educated women are even higher than those of men. However, by the age of 30 there is an employment gender gap equal to $15 \%$ for the oldest cohorts and to $7 \%$ for the youngest one. The gender gap along the life cycle has a U-shape, and by the 40s, the employment gap seems to shrink again, although parity in employment rates is never reached at older ages. This figure, and the timing of lower female participation, suggests that family and child bearing may be the reasons for the different time-profile of participation. The evolution across cohorts, suggest on the other hand that more recent generation have been affected less by family constraints in their labor participation.

\subsection{Part-Time versus Full-Time Jobs along the life cycle}

Family issues are very likely to affect not only the extensive margin of labor supply (employment) but also the intensive margin (hours worked). Given that childcare is very time intensive and competes with time for work, family issues may entail a reduction in hours worked, as has been already shown by related studies for the U.S. (see Goldin et.al 2010). Part-time versus Full-Time Work indicates, in absence of precise measures of actual hours worked, a usual

\footnotetext{
${ }^{3}$ Given the data availability we can construct 4 different cohorts, five years apart from each other, and thus cover from those born between 1960 and 1975. Moreover, since we have constructed 7 age categories that group 3 years each, the cohort born in 1960 refers to those individuals born between 1959 and 1961 and that are between 25 to 27 years of age in 1986. The same applies for the rest of cohorts.
} 
approximation of time dedicated to work. Figure 3 describes Life Cycle Part-Time Rates (as a \% of employment for college-educated women) ${ }^{4}$.

Two issues deserve notice: First, part-time has been increasingly used by recent cohorts at all ages. Second, among college-educated workers, we observe an increasing pattern with age. This confirms the fact that the youngest generations of women use part-time employment to a greater extent especially at child-bearing ages presumably to reconcile work and family. Indeed, this is confirmed by the percentage of women indicating "family reasons" as the reason for part-time in the Labor Force Survey. In 1996, only 15\% of college-educated females aged 35-39 gave such a reason for working part-time. However, by 2011, 45\% of part-timer was due to family reasons. This increase was also encouraged, after 1998 by the Law on part-time, which improved the working conditions for part-timers and encouraged more females to make use of such work pattern.

\subsection{Gender Gaps in the access to Managerial Jobs along the Life-Cycle}

In order to complete the descriptive information provided in this section, we describe the incidence of college-educated men and women in managerial jobs and we look at possible occupational changes along their life cycles ${ }^{5}$. Gender gaps in the access to top jobs may somehow reveal differences in the labor market performance of college men and women along their life cycles and for different birth cohorts. Figure 4, shows the percentage of workers employed in managerial jobs. It shows that on average, the incidence of these jobs is very low. However, when looking at different age groups, we can see a clear increase in the prevalence of managerial jobs with age. Moreover, this increase is more pronounced in the later cohorts than in the oldest ones.

Finally, when comparing men and women along the life cycle, we can see from Figure 5 that there is a clear decrease in the relative presence of women in managerial jobs with age, and the pattern is similar across cohorts. Given the age at which this decline begins this profile might suggest that raising a family becomes harder to reconcile with a high profile career over time.

\section{The impact of Children on Gender Gaps in Labor Supply and in Labor Market Performance}

In this section we quantify the impact of having children on the gender gap in the labor market indicators mentioned above - employment rate, incidence of part-time, wages and presence in managerial jobs. For doing so, we make use of two micro-data sets: The first one is the first wave (1994) of the Spanish data from the European Household Panel, and the second corresponds to the 2008 wave of

\footnotetext{
4 We do not provide either evidence of Part-Time Rates for college males or relative Male/Female part-time rates because they are negligible at all ages and for all birth cohorts for the male population. They are available upon request.

5 Unfortunately, although gender wage gaps are an additional clear indicator of differences in performance in the labor market by men and women, the lack of available data for Spain prevents us to describe gender wage gaps along the life cycle and for different birth cohorts.
} 
the Spanish data of the European Survey of Living Conditions. One of the advantages of using these panels is that their design is the same which makes them highly comparable. In addition, these two European Household Panels are most suitable for our study given that they are the unique datasets for Spain which contain individual information on demographic characteristics, labor market performance and family information together.

We have used these waves in order to compare the mid-nineties with the most recent tendencies measured as of 2008, the last available wave of the EUSILC 6 . The college-educated individuals included in the 1994 sample, whose age is between 25 and 45 years of age back then, belong to the two oldest birth cohorts described in section 2 - (aged between 60s and 65 by 2008), whereas those included in the 2008 sample are individuals who belong to the two latest cohorts born in the 1970s and 1975s. Changes in the condition of women with respect to their role in the family and in the labor market have been remarkable during this 15 year period.

\subsection{Average Gender Gaps: 1994 versus 2008}

Before getting into the estimation of the impact of children on the observed Gender Gaps, it is interesting to look at the raw average gaps for the relevant groups of men and women and for the two periods under consideration. Our main goal in this Chapter is to measure the extent to which rearing children affects the gender gaps for the highly educated men and women. Hence we have restricted individuals to be between 25-45 years of age, when family concerns should matter most, and we focus on those individuals with the highest level of education (ISCED 5-7) ${ }^{7}$.

Table 1 presents the average Employment Rates, Part-Time Employment Rates and percentage in Managerial Positions (following the corresponding ISCO classification of occupations for each period) for different groups of collegeeducated individuals namely all Men, all Women, Men and Women without children and Men and Women with children ${ }^{8}$. Average gender gaps are reported for all individuals and separately depending on the family situation. We will call "family gap" the differences in average values between childless women and mothers.

Table 1 reveals interesting features for each of the indicators that we summarize next.

Employment Rates: There was a substantial increase in employment rate of all college women between 1994 and 2008. This increase was equal to 17 percentage points (pp.) for women with children whereas for childless women the increase

\footnotetext{
${ }^{6}$ At the same time, the period under study in this section corresponds basically to the one presented in the descriptive part of the chapter, which facilitates somehow the interpretation of the results and helps relating them to the stylized facts already shown in the previous sections.

7 This is the most standard age interval of other studies which have analyzed the impact of children on gender issues, see Harkness and Waldfogel (2003), and Moluenga and Molina (2009) among others.

${ }^{8}$ With children refers to having at least one, regardless of the total number of children or their age.
} 
was equal to $11 \mathrm{pp}$. The employment rate of men, to the contrary, remained very stable and high between these two years. With respect to gender gaps, these are particularly high among men and women with children (31\% in 1994), although by 2008 the gap decreases to $14.4 \%$. It is also interesting to observe that the gender gap in the employment rate among men and women with no children disappears by 2008. Finally, comparing women with and without children - the family gap- we can observe that it is substantial in 1994 (11\%), but it decreases by a large extent (to $5 \%$ only) by 2008.

Part-time employment Rates: Both in 1994 and 2008, part-time employment was basically a Female choice. The incidence of part-time employment among collegeeducated male workers - fathers or not- was negligible. However, for women with children the increase in the use of part-time between the earlier and the later year employment was substantial (from 11 to 19\%), whereas for childless women the contrary can be observed - a decrease from 15 to 11\%. This evidence suggests that the increase in Part-Time Employment was strongly and positively correlated with the presence of children. These gender gaps reflect mainly the evolution of parttime employment for women. Finally, the family gap in the use of part-time increased considerably. The introduction of part-time laws certainly played and important role in this evolution.

Access to Managerial Jobs: The first feature to highlight from the last two columns of Table 1 is that the presence of college-educated men and women aged 25-45 years working in managerial jobs is very low. There are simply very few managers below the age of 50. For women with children the presence among managers is virtually zero, while 1 to 2 percent of women without children are managers. For comparison 7\% of men aged 25-45 were managers in 1994 but by 2008 only 3\% was. The presence among managers was higher for men with children than for childless men. Contrary to what we observed with the part-time employment indicator, in this case the evolution of the gender gap over time reflects mainly changes in the percentage of males in these jobs, given that women are barely represented in these occupations, particularly if they have children. This is consistent with the descriptive figures we depicted in section 2, although the percentages there were somewhat higher for both groups, which could be associated with the selected age range of our sample of individuals.

Table 2 shows descriptive evidence for wages, namely (Log) Hourly Wages. When comparing log hourly wages of men without and with children, the first issue to highlight is that fathers earn more than childless men in the two periods, whereas the contrary happens for women. With respect to the gender wage gap, it is slightly higher in 2008 than in 1994 - it rises from $3.2 \%$ to $4.5 \%$. In addition, comparing men and women without children, it can be seen that childless women earn more than their male counterparts in 1994 (6\% more), but by 2008 the gender gap reverts sign, favoring men in around 5\%. When comparing men and women with children, men earn between 5 and 6 percent more in the two periods under consideration. Finally, note that these gender gaps are much lower than those observed for the whole population of men and women. In this case education seems to reduce the hourly wage gap. 


\subsection{The impact of children on each of the Labor Market Indicators}

We now proceed to isolate the impact of children on gender gap in labor market performances, distinguishing it from other potential determinants. Tables 3 and 4 present discrete choice (Probit) estimations of (i) Probability of Working versus Non-working and (ii) Probability of Part-Time versus Full time Employment ${ }^{9}$. Table 5 presents standard hourly wage regressions. In all estimations, we consider the sample of college-educated men and women of 25-45 years ${ }^{10}$.

Depending on the specification, controls for age, presence of a working spouse, other family income and regional fixed effects are also included. Our final preferred family specification is captured by the variable "Any child" a dummy equal to one if the family has any number of children of any age ${ }^{11}$. Estimations are done separately for 1994 and for 2008 to compare the impact of having children for the three indicators in the two periods. Given the potential simultaneity of the decisions to have children and the decision relative to the labor market we must instrument the children variable to avoid spurious correlations due to reverse causality in the estimation equation. We try two instruments:

- IV1: Following Harkness and Waldfogel (2003) we use as an instrument the fraction of women who have any child by region, age and marital status (married or not). The identification assumption is the local (regional) culture about having children affects the individual decisions of having children but not the local labor market conditions. Clearly if the regional fertility averages are affected also by economic (labor market) conditions the instrument would not be valid.

- IV2: Second we also try an instrument based on the Spanish Time Use survey of 2002-2003. To be consistent with our estimation sample, we restrict to individuals aged 25-45 and compute average daily time devoted to housework by region (18 regions), gender, age range (25-34 and 35-45) and type of household (presence of children or not). This allows creating 144 different cells with different values with respect to time devoted to housework. In this case the identifying assumption is that the time spent in house-work (rather than the number of children) identifies local cultural attitude towards women and family and can be correlated with fertility decisions. Then we merge these values with the two Household Panels for year 1994 and 2008. The correlation of this variable with the variable Any Child measured in 2008 is

\footnotetext{
${ }^{9}$ We have decided not to report the impact of children on the incidence in managerial jobs because the barely null incidence of women in these jobs prevents the identification of any significant effect. Nevertheless, results can be obtained from authors upon request.

10 Tables 3 and 4 display the marginal effects of the variables related with having children, as well as the marginal effect of children for different groups: women with children versus women without children - marginal contribution to the family gap, and women versus men - marginal contribution to the gender gap. Table 5 displays the OLS and IV coefficients of the wage regressions.

11 We estimated also other specifications, allowing the impact of the family to depend on the age of the child. We found that, conditional on the age of the mother, the impact of very young children on employment is marginally higher than that of older kids. Given that the additional contribution is small, we finally decided to present only the average impact of any child on employment. Results on the other specification can be obtained from the authors upon request.
} 
0.227, significantly lower than the corresponding correlation with the other instrument, but still significant considering that the variable is extracted from a different data source and a different time period. Indeed, in the selection estimation of Any child on this instrument (once the controls are added), it turns out to be statistically significant, with a value of 0.242 and a standard error of 0.031. However, we encounter some data limitations for the year 1994, given that in the Household Panel for that period, the regional information available covers only 7 regions instead of 18 autonomous communities. This reduces the number of cells to 56, which introduces very limited variability when merging these values with the 1994 Household Panel. Indeed, the correlation between this potential instrument and Any Child for 1994 is 0.067, and insignificant in the selection estimation. Therefore we will present IV1 and IV2 results for 2008, but only IV1 results for 1994.

The computational method that we use to calculate the IV1 and IV2 estimates is two-stage least-squares (2SLS). In the first stage, Any Child is regressed on all of the exogenous control variables by using a probit model, including also the instrument in the equation of interest. After obtaining the predicted values of that equation, in the second stage, the regression of interest is estimated as usual, except that the endogenous variable is replaced with the predicted values from the first stage. From the results of the first stage estimation, we can assure that the instrument is a good predictor of the endogenous variable ${ }^{12}$ - Any Child. Unfortunately, the additional requirement for the instrument to be valid (it should be uncorrelated with the error term in each equation of interest) is not testable in exactly identified models as we have here.

We report the results of the estimations in Tables 3 and 4. The first column for each of the two periods - column [1]- shows the marginal effect of children when no additional controls are included. Columns [2], [3] and [4] report adjusted marginal effects of having children, when including the additional set of controls in the estimation. In column [2] we assume exogeneity of the children variable whereas in [3] and [4] we use 2SLS to account for the possible endogeneity in the decision of having children. Column [4] corresponds to the estimation using the second instrumental variable and it is only reported for year 2008.

\subsubsection{The Impact of Children on the Employment Decision}

Results from Table 3 indicate that in 1994, having any child decreased the probability of working for women with respect to men by around $22 \%$ - coefficient of Female*Any child in the third raw of the table. By 2008, this differential increased to $26 \%$ - the estimated impact is very similar regardless of the different instruments used, which adds robustness to the result. However, the total gender gap, which is composed of the specific gender effect plus the children differential effect for women, decreases from $28 \%$ in 1994 to $24 \%$ by 2008 . This is because the specific gender effect - coefficient of Female, decreases significantly from 1994 to 2008. In addition, when comparing mothers with childless women (family gap),

\footnotetext{
${ }^{12}$ To verify that the chosen instrumental variable is not weak we compute the F-statistic against the null that the instrument is irrelevant in the first-stage regression which turns out to be much larger than 10 , what ensures that the instrument is a good predictor of the endogenous children variable.
} 
the fact of having children decreases the probability of working by $10 \%$ in 1994 , but interestingly, the impact of children by 2008 is even higher - reduces the probability of working in $17 \%$.

Our interpretation of these results is as follows: In 1994 college women who entered the labor market were a higher selected sample than in 2008 - average employment rates of childless women were $11 \%$ lower than comparable men (the gap shrinks to $1 \%$ by 2008), and average wages of childless women were higher than those of childless men (the opposite in 2008). As a result, the impact of children is comparatively smaller in 1994 than in 2008, although in the two periods children clearly decrease the probability of working for women. By 2008, given that there is no gender gap at entrance in the labor market among college individuals, the presence of children is basically responsible for the whole gap. As a result, the impact of children is higher and the family gap is also higher.

\subsubsection{The Impact of children on the Decision of working Part-Time}

Table 4 presents the estimations on the impact of children on the Part-Time versus Full-Time choice for those who have decided to remain in the labor force. The most interesting result is that the impact of children in the use of Part-time employment for women with respect to men (coefficient of Female*Any child) is not significant in 1994, but increases to $13 \%$ by 2008 . In addition, and consistently with this (given the small incidence of Part-Time work among men), having children did not increase the use of Part-time employment for women in 1994 (which is consistent with the lower part-time employment rates for women with children with respect to childless women observed in table 1) but it did by 2008. If we consider the whole adjusted gender gap in part-time rates i.e., the specific gender plus the family effect, this amounts to $7 \%$ in 1994 and rises to $22 \%$ by 2008, where the specific female effect is added to the significant family effect. Again, very similar results are found regardless of the instrument used in the IV estimation for 2008.

Overall, by 2008, a large share of women in the labor market who have children use Part-Time Work to reconcile family and career. They did not do so in 1994 probably because the possibilities of part time jobs were much more limited ${ }^{13}$, so many more women decided to quit the labor force. In fact the frequency of those college women who report to work part-time because of housework, looking after children or other persons increases in 50\% in this 15 years period - in particular, it goes from $23 \%$ in 1994 to $73 \%$ in 2008

\subsubsection{The impact of children on Gender Wage Gaps}

Table 5 shows the estimate of the presence of children on the observed gender wage gap. Estimations for 1994 and 2008 are presented separately. In column [1] we present only indicators of family to obtain the impact of children in the raw

\footnotetext{
${ }^{13}$ We have not taken into account the possible selection of women into the labor market in this estimation because our aim is not to infer the decision of part-time for all college women, but rather the determinants of this decision for women who have already decided not to quit from the labor market. Our aim is to measure to what extent women with children who have decided not to quit from the labor market decide to go on part-time to facilitate family and work life. The same applies to the estimation of the incidence in managerial jobs, as well as the wage estimations.
} 
wage gap. Column [2] adds the standard controls (age and its square, tenure, parttime employment, industry dummies and regional dummies) but without conditioning on occupation. Column [3] adds controls for occupation. The aim for presenting these two specifications separately is to measure the extent to which part of the gender gap in wages is due to the fact that women segregate into low paid occupations. Finally, column [4] reports the IV estimation corresponding to this last specification. We just present the IV1 results for both periods, since the IV2 is only used for 2008 and the results are pretty similar when we use that instrument instead.

The most interesting reuslt is that the impact of the family differs to a great extent when comparing 1994 with respect to 2008. In 1994, there is no significant gender wage gap between childless women and men (coefficient of female of columns [3] and [4]). However, the presence of children decreased female wages by around $13 \%$ when compared to their male counterparts. In 2008, results are just the opposite: The adjusted gender wage gap between childless women and men is significant ( $9 \%$ without conditioning for occupation and $6 \%$ conditioning for it) but the impact of children is negligible. This result is very consistent with what we saw in the estimations of the employment probability: As we argued before, in 1994 there is high positive selection in labor market entrance of college women, which results in average higher wages for them and hence in no gender wage gaps. Hence the whole wage gap is due to the impact of children. By 2008, given that there is no selection at entrance for college women, the wage gap is basically at entrance (childless men and women), with no negative impact of children for female wages.

It is also interesting to see the different correlation between Part-Time and hourly wages in 1994 and 2008. In 1994, part-time employment's impact is either positive or null, depending on whether we condition for occupation or not. However, by 2008 , its impact is clearly negative, which is a more usual result. Given the low incidence of part-time work in 1994, it is likely that workers who made use of it were a very particular sample of workers. Finally, when comparing the impact of children on wages with and without controlling for occupation (2digit disaggregation of the corresponding ISCO classification for each year) columns [3] and [4], we find very small differences. This means that gender gaps in wages of college individuals are not driven by segregation of women with children in low paid occupations to reconcile family and work.

\subsection{Contribution of the Family to the Average Gender Gaps}

To complete the section we quantify the absolute and relative contribution of children to each of the raw average gaps, based on the estimations presented above. This way of quantifying the impact of interest allows us to measure by how much differences in the labor market indicators between men and women can be explained by differences in their response associated with having children. In the case of wages the contributions are computed by simply multiplying the estimated coefficients of having children by the mean frequency of having children in the sample for men and women respectively. However, given that for Employment Rates, Part-time employment Rates and Incidence of Managerial Jobs the estimated models are non-linear, the absolute contribution of children to the average gap is 
obtained following Yun (2004), who uses an extension of the Oaxaca Decomposition Method to account for non-linear estimations ${ }^{14}$. In practice, to compute the absolute contributions we just need to multiply the estimated coefficient of interest by a proper weight, which in this context is the standard normal probability density function evaluated at the mean predicted characteristics. The relative contribution is the ratio between the absolute contribution and the raw corresponding average gap. The computed contributions are presented in the last raw of Tables 3-5 both for the most general specification that includes controls and for the IV estimates.

The first thing we observe is that the relative contribution of the family to the employment gender gap was very small in 1994 but increases to $56 \%$ by 2008 . However, note that average gender gaps in employment are much higher in 1994 than in 2008. Second, for those women who decide to stay in the labor market, having children contributes to explaining $4 \%$ of the gender gap in part-time work use in 1994, but this increases to $9 \%$ by 2008 . Although the contribution of the family is not very remarkable in the two years, it is interesting to observe that in 15 years it has doubled, whereas the gap has remained quite stable. This means that college women with children are increasingly using part-time jobs to remain in the labor market instead of quitting for childcare issues. Finally, whereas average gender wage gaps have doubled in these 15 years, the contribution of the family to it has decreased substantially: having children contributed to explaining $85 \%$ of the average gender gap in wages in 1994 , whereas by 2008 , the family does not explain it at all.

\section{Policy Implications}

The results reveal that by 2008 college women perform very similarly to men when entering the labor market in their labor supply decisions - the employment rates of childless college men and women are very similar. However, in the intensive margin, childless women still use part-time jobs more extensively than their male counterparts ( $11 \%$ versus $2 \%)$. In addition, men on entrance earn approximately $5 \%$ more than their female counterparts. One important question is to identify the underlying reasons for these differences when family needs still do not play a role. Is it a supply-driven or a demand-driven decision, that of working part-time? The proportion of childless women who report working part-time because they cannot find a full-time job was $42 \%$, which clearly indicates that at least for many childless women, there are demand restrictions which prevent them working on full-time basis. Therefore, there seem to be room for policy actions directed to improve the intensive margin of female labor supply. With respect to differences in the hourly wage, Peri and Anelli (2012) show that differences in the chosen fields of study in college between men and women (in Italy) is the reason for a significant part of the observed wage differential. This might be perfectly applicable to Spain, given that the facts observed in Italy are very similar to those observed in Spain. If this different behavior is entirely due to differences in

\footnotetext{
14 There are alternative ways of decomposing probit functions, see Even and Macpherson (1990), Nielsen (1998), but the one proposed by Yun(2004) is the most suitable in our setting since the emphasis of our approach relies on decomposing the differences into coefficients effects.
} 
preferences, there is not much to be done from a policy perspective. Rather, if females do not engage in these studies because they perceive future discrimination in those occupations as some studies suggest (see The National Academy Press, 2007), then there is scope for improvement by encouraging women to engage in more technical studies and to choose science and math intensive college majors.

The first important result, to draw some policy implications is that by 2008 the observed gap in employment rates - whereas negligible between childless men and women was still equal to $14 \%$ between fathers and mothers, and that the presence of children accounted for $56 \%$ of this gap. This indicates clearly that the presence of children leads many women to quit the labor market still as recently as 2008. Society needs that firms and other institutions develop possible mechanisms to combine family and work and hence allow mothers to participate in the labor market as much as fathers in terms of their extensive margin if they wish to do so. This can be achieved by developing flexible timing work schedules and home-work practices (tele-trabajo) not only for mothers, but also for fathers. Even though some big firms are slowly starting to implement these measures, there is still a long way to go for Spain. Only if these mechanisms are widely available for mothers and fathers, women with children will be able to access working careers similar to their male counterparts. As we already said in the introduction, a shrinking working-age population and the high educational level achieved by women in the last few decades, make it essential to consider women as a fundamental part of the workforce.

The second important result of this study is that by 2008 the use of part-time for mothers has increased substantially (from $11 \%$ in 1994 to $19 \%$ by 2008). At least partly this may be a result of the 1998 Part-Time Law, which introduced the following changes with regards to part-time jobs: (i) part-time job decisions had to be the result of a voluntary acceptance by workers, (ii) employers had to provide information to the Workers Committee with regards to additional hours worked by part-time workers, (iii) Social Security contributions for additional hours were included in the calculation of contribution periods for entitlement to Social Security benefits, (iv) discrimination against part-time workers in terms of social welfare protection was reduced in regard to retirement pensions and permanent invalidity benefit, since the number of days contributed for the purposes of establishing regulatory bases for such pensions and benefits is now multiplied by 1.5 , and (v) job stability in part-time contracts was reinforced with incentives for indefinite contracts and the changeover from short-term part-time contracts to indefinite ones.

These reforms have probably made it easier for mothers to combine family and work. In 2007, the Gender Equality Law introduced some provisions concerning paternity leave and childcare leave which have allowed and encouraged work reductions for mothers and fathers with small children. The next challenge for the future, particularly for the highly educated population, is not so much about allowing leave from work. It is rather about developing flexibility measures which enhance the possibility for women to remain in the labor market and make it possible to develop career paths similar to those of men if they wish to do so. 


\section{Summary and Conclusions}

In this paper, we explore the trade-offs between family needs and work career development for highly educated men and women in Spain. Although women reached, as in other countries such as Italy or the US, higher educational attainments in terms of graduation rates from college their careers often diverge substantially from those of men. Family issues are undoubtedly an important determinant of this divergence. Women must combine employment with home responsibilities to a much larger extent than their male partners and this conditions their decisions with respect to their labor supply and hence to their labor performance in the future.

We present evidence of gender gaps in labor supply (employment rates, use of part-time), wages and incidence in managerial jobs along the life cycle and for different cohorts - those born in 1960, 1965, 1970 and 1975. This allows to compare gender gaps at different ages, in particular, at pre- and post-child bearing ages and to observe whether they increase in this period - from 30 to 40 . This provides a preliminary picture of the role of family issues in the professional careers of women versus those of men. Second, by comparing gender gaps along the life cycle for different birth cohorts we can assess changes over time in the way Spanish Women combine family and work. In addition to this descriptive evidence we use two micro-datasets to account for the impact of having children, on the observed gender gaps. The first one is the first wave of the European Household Panel for Spain - 1994, and the other one is the 2008 wave of the European Survey of Living Conditions. Both of them share the design and hence are highly comparable. The use of these two datasets is very convenient because, given that we consider college men and women of 25-45 years of age, the 1994 sample captures the behavior of men and women born between 1950 and 1970, which on average reflects the behavior exhibited by our two earlier cohorts - born in 1960s and 1965s. On the other hand, the sample of 2008 captures the behavior of collegeeducated men and women who were born between 1963 and 1983 and hence basically reflects the behavior of the two youngest cohort in the descriptive sample.

Our findings suggest the following insights: First, with respect to gender gaps in the extensive margin of labor supply - employment rates, we observe a very different pattern when comparing the mid-nineties (1994) to late 2000s (2008): In the former, gender gaps in employment rates are quite substantial even among childless men and women - 11\%, which increase to a large extent - 31\% when comparing mothers with fathers. Children account only for $11 \%$ of this substantial gap, which tells us that besides children there are many other issues - social norms or others, which affect this different behavior. However, by 2008, the pattern of gender gaps in employment rates has changed substantially: there is basically no gap between childless men and women, although this rises to $14 \%$ between fathers and mothers. Furthermore, children account for $56 \%$ of this gap. In summary, it looks as if by 2008 women on entrance in the labor market behave very similarly to men, but family issues lead some women to quit the labor market. 
Second, for those men and women who stay in the labor market, we look at gender gaps in labor supply in number of hours worked, proxied by part-time employment rates. The data reveals, that the use of part-time employment is basically a female choice, the use of part-time employment among men is negligible. At this stage, we see interesting differences in the behavior of women with respect to the use of part-time work in the mid-nineties as compared with the late 2000s: on the one hand, the use of part-time employment was higher among childless women as compared to mothers (15\% versus $11 \%)$, which suggests a very small, if any, connection between family issues and part-time work at that time. This has changed completely by 2008 , when the use of part-time employment of childless females is only $10 \%$ but rises to $18 \%$ for mothers. Additionally, children account for $4 \%$ of the gap in 1994 and $9 \%$ of it by 2008 . The fact that children accounts only for $9 \%$ of the gap even in 2008 suggests that although children is an important determinant for the choice of part-time employment versus full time work, there may be other determinants, among others demand restrictions, which lead some women work on part-time basis.

Third, with respect to the performance in the labor market, we compare hourly wages of college-educated men and women. The first interesting issue that we observe is that in the mid-nineties, childless women earned on average $6 \%$ more than men, which suggests that these women were a high selected sample among college females. However, when we compare fathers with mothers, the gap was $7 \%$ in favor of men. Furthermore, children account for $85 \%$ of the gap. By 2008, the pattern was different: the gender gap between childless men and women was of the same magnitude than that among fathers and mothers $(5 \%$ in favor of men) and children did not contribute to explain the gap. The reason for it could be discrimination or differences in unobserved skills. Our data does not allow looking empirically at these possibilities, but both of them might be potential reasons for the observed wage gaps. 


\section{References}

[1] Azmat, Ghazala, Maia Güell and Alan Manning. (2006) "Gender Gaps in Unemployment Rates in OECD countries” Journal of Labor Economics vol 24 no.1: 1-37.

[2] Bertrand, Marianne, Claudia Goldin and Lawrence F. Katz. (2010) "Dynamics of the Gender Gap for Young Professionals in the Financial and Corporate Sectors". American Economic Journal: Applied Economics 228-255.

[3] De la Rica, Sara, Brindusa Anghel and M. Alloza. (2011) "Diferencias de Género en la Formación Científica Evidencia Empírica” Situación de las Mujeres en la Ciencia Española - Libro Blanco (Unidad de Mujeres y Ciencia) Capítulo 2.

[4] División General de Renovación Pedagógica. (1992) "Las Desigualdades en la Educación en España”, Ministerio de Educación y Ciencia.

[5] Escot, Lorenzo, Ricardo Gimeno and R. Mateos de Cabo. (2011) "Disentangling Discrimination on Spanish Boards of Directors”. Corporate Governance: An International Review, 2011, 19(1): 77-95

[6] Even, William E. and David A. Macpherson. (1990) "Plant Size and the Decline of Unionism," Economics Letter, 32, 393-398.

[7] Fuchs, Victor. (1988) “Women’s quest for economic equality” Cambridge: Harvard University Press.

[8] Goldin, Claudia. (2005) "From the Valley to the Summit: The Quiet Revolution that Transformed Women’s Work” Regional Review. 14:3, pp. 5-12.

[9] Goldin, Claudia, Lawrence F. Katz and Ilyana Kuziemko. (2006) "The Homecoming of American College Women: The Reversal of the College Gender Gap”. Journal of Economic Perspectives - Volume 20, No. 4 pp. 133-156.

[10] Goldin, Claudia. (2006) “The 'Quiet Revolution' that Transformed Women's Employment, Education and Family”. American Economic Review, 96 (2): 1-21.

[11] Goldin, Claudia and Lawrence F. Katz. (2008) "Transitions: Career and Family Life Cycles of the Educational Elite”. American Economic Review, 98:2, 363369.

[12] Harkness, Susan and Jane Waldfogel. (2003) "The Family Gap in Pay: Evidence from Seven Industrialized Countries” Research in Labor Economics, 22, 369-414.

[13] Herr, Jane, and Catherine Wolfram. (2009) “Opt-Out Rates at Motherhood across High-Education Career Paths: Selection versus Work Environment.” National Bureau of Economic Research Working Paper 14717.

[14] Instituto de la Mujer. (2009) “Mujeres en Cifras”, Ministerio de Igualdad. 
[15] Joshi, Heather. (1991) "Sex and motherhood as handicaps in the labor market". Women's Issues in Social Policy. London: Routledge.

[16] Joshi, Heather, and Newell, Marie-Louise. (1989) "Pay Differentials and Parenthood: Analysis of Men and Women Born in 1946”. Coventry: University of Warwick Institute for Employment Research.

[17] Molina, José Alberto and Víctor M. Montuenga. (2009) "The Motherhood Wage Penalty in Spain”. Journal of Family Economic Issuess 30:237-251.

[18] Neumark, David and Sanders Korenman (1994). "Sources of bias in women's wage equations: Results using sibling data”. Journal of Human Resources, 29, 379-405.

[19] Nielsen, H. S. (1998) "Discrimination and detailed decomposition in a logit model”. Economics Letters, 61, 115-120.

[20] OECD Employment Outlook (2002) Chapter 2 - ISBN 92-64-19778-8

[21] The National Academy Press. (2007) "Beyond Bias and Barriers: Fulfilling the potential of women in academic science and engineering”, Washington, D.C

[22] Waldfogel, Jane. (1998) “Understanding the 'Family Gap' in Pay for Women with Children,” Journal of Economic Perspectives, vol. 12: 137-156.

[23] Wood, Robert G., Mary E. Corcoran, and Paul N. Courant. (1993) "Pay Differences among the Highly Paid: The Male-Female Earnings Gap in Lawyers' Salaries.” Journal of Labor Economics, 11(3): 417-41.

[24] Yun Myeon-Su (2004). "Decomposing Differences in the First Moment." Economic Letters, Vol. 82: 275-280.

[25] Yun, Myeon-Su (2000). "Decomposing Analysis for a Binary Choice Model”. Working Paper, No. 2000-01, Department of Economics, Rutgers University. 
Figures and Tables

Figure 1 - Life Cycle Employment Rates (\%) - College Educated Women

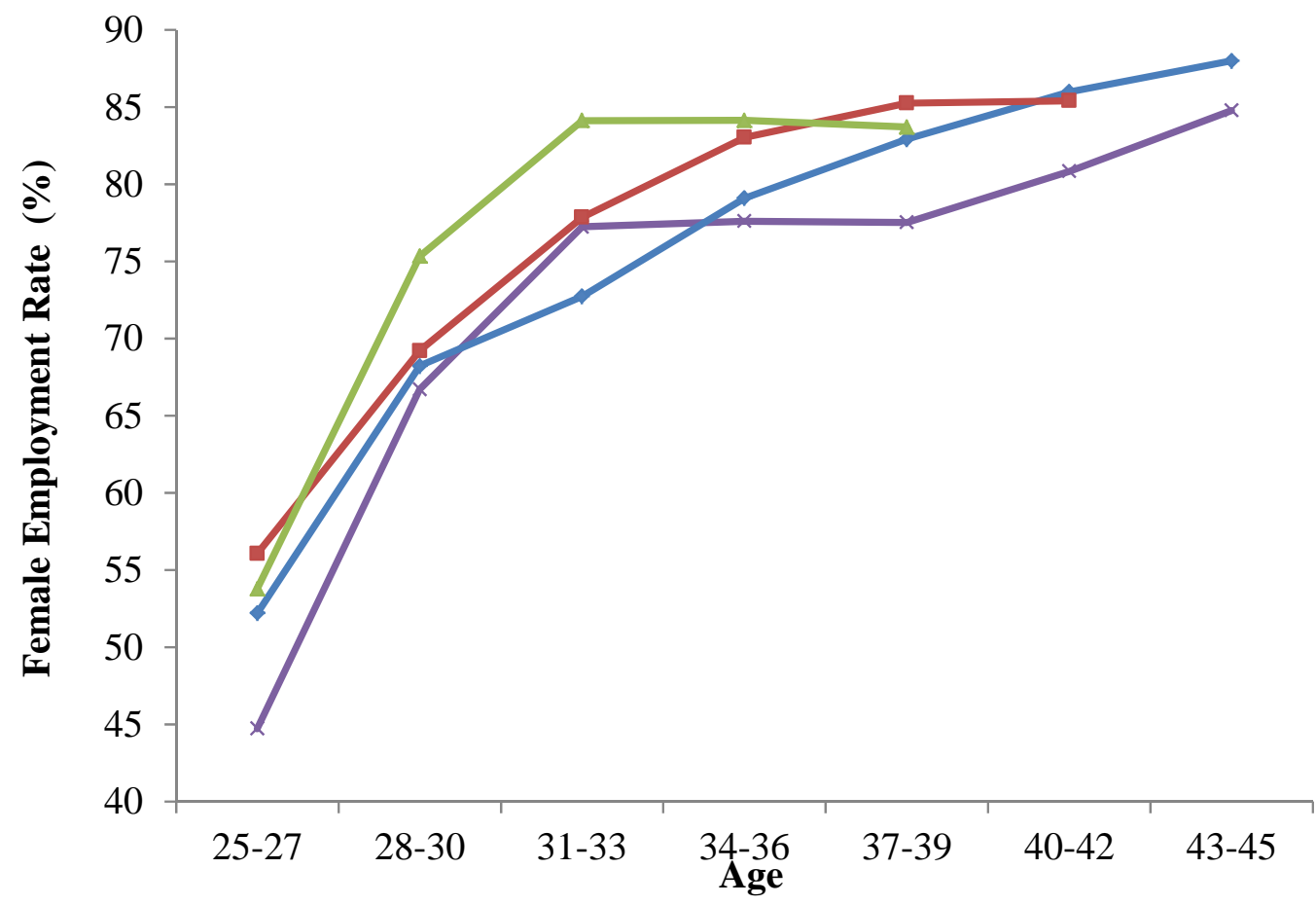

$\longleftarrow$ Born in $1960 \multimap$ Born in $1965 \multimap$ Born in $1970 \leftrightharpoons$ Born in 1975

Source: Encuesta de Población Activa (INE) 1986-2011

Figure 2 - Life Cycle Relative Female Employment Rates (\%)

- College-Educated Women/Men

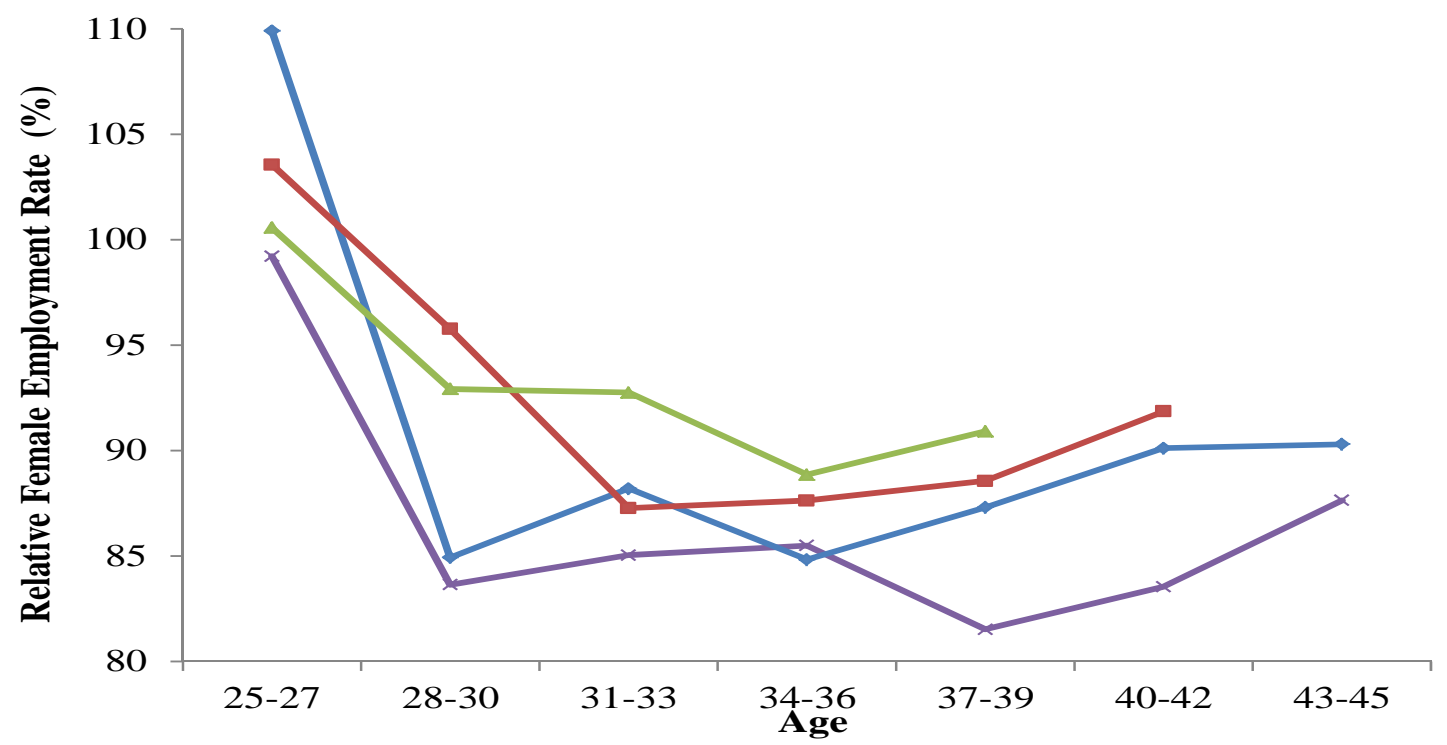

$\because$ Born in $1960 \multimap$ Born in $1965 \multimap$ Born in $1970 \multimap$ Born in 1975

Source: Encuesta de Población Activa (INE) 1986-2011 
Figure 3 - Life Cycle Part-Time Rates (as \% of employment) - College-Educated Women

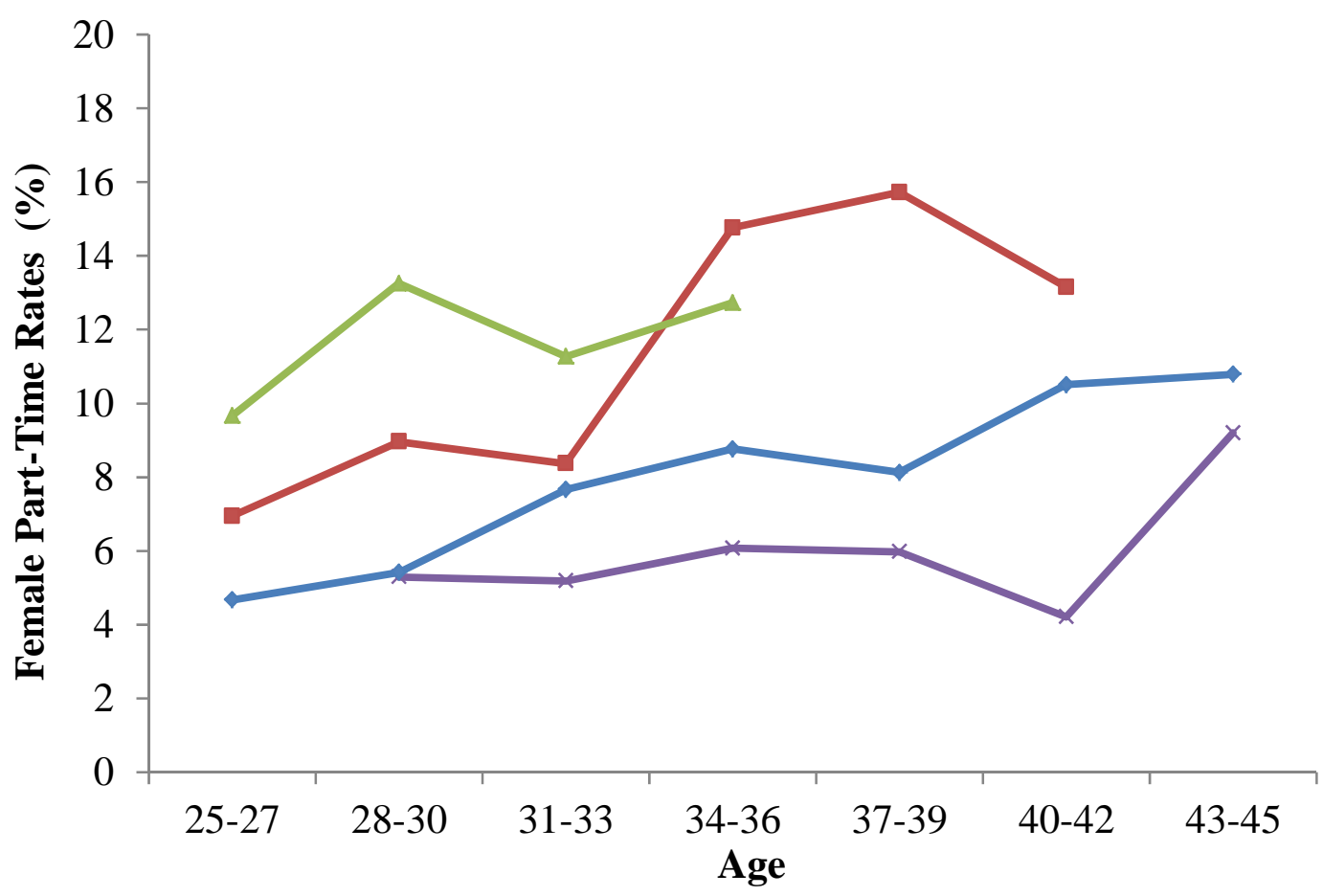

*Born in $1960 \multimap$ Born in1965 $\rightarrow$ Born in $1970 \multimap$ Born in 1975

Source: Encuesta de Población Activa (INE) 1989-2011

Figure 4 - Life Cycle Incidence of Workers in Managerial Occupations - College-Educated Females

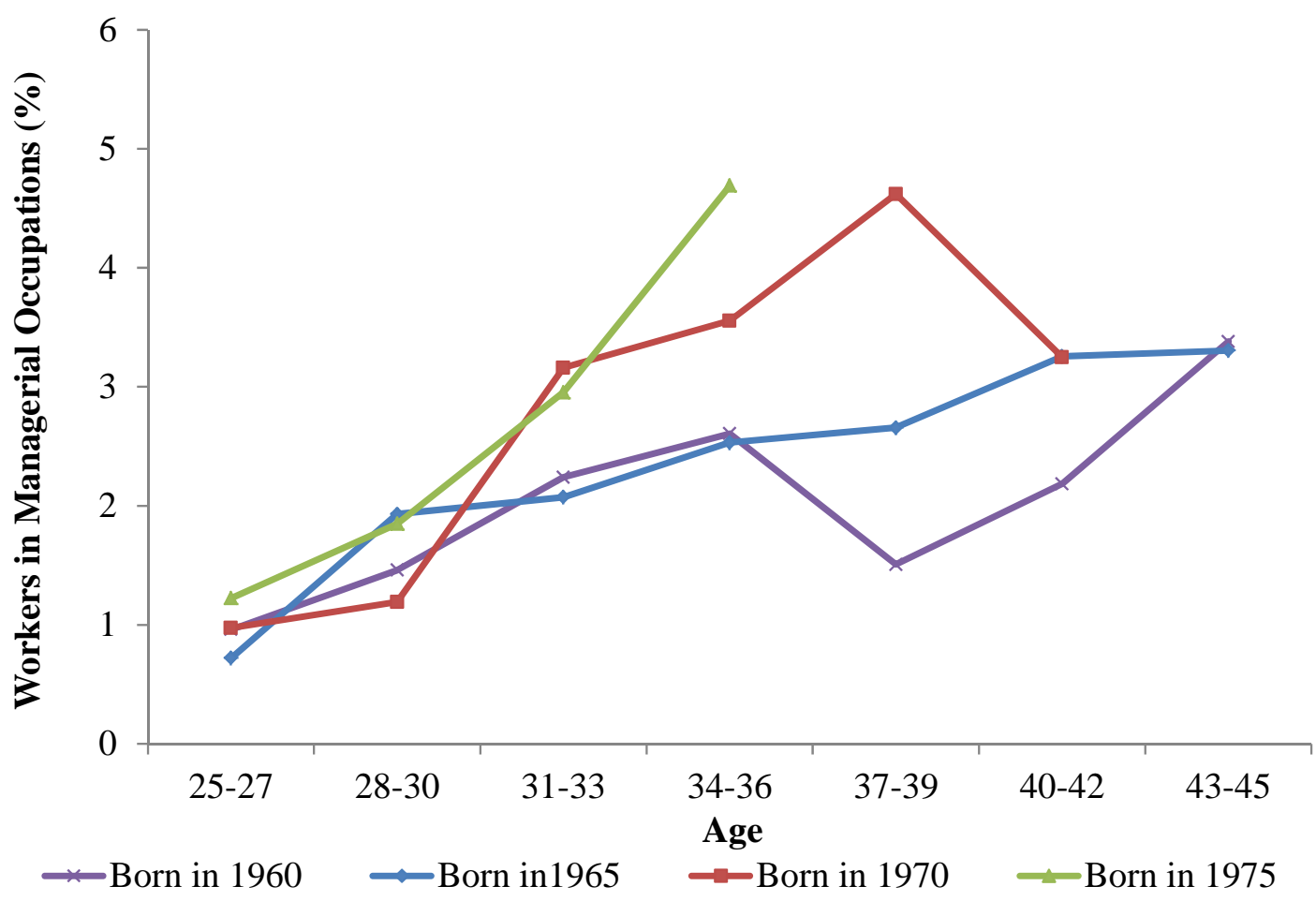


Figure 5 - Life Cycle Relative Incidence of Females Working as Managers - College-Educated Women/Men

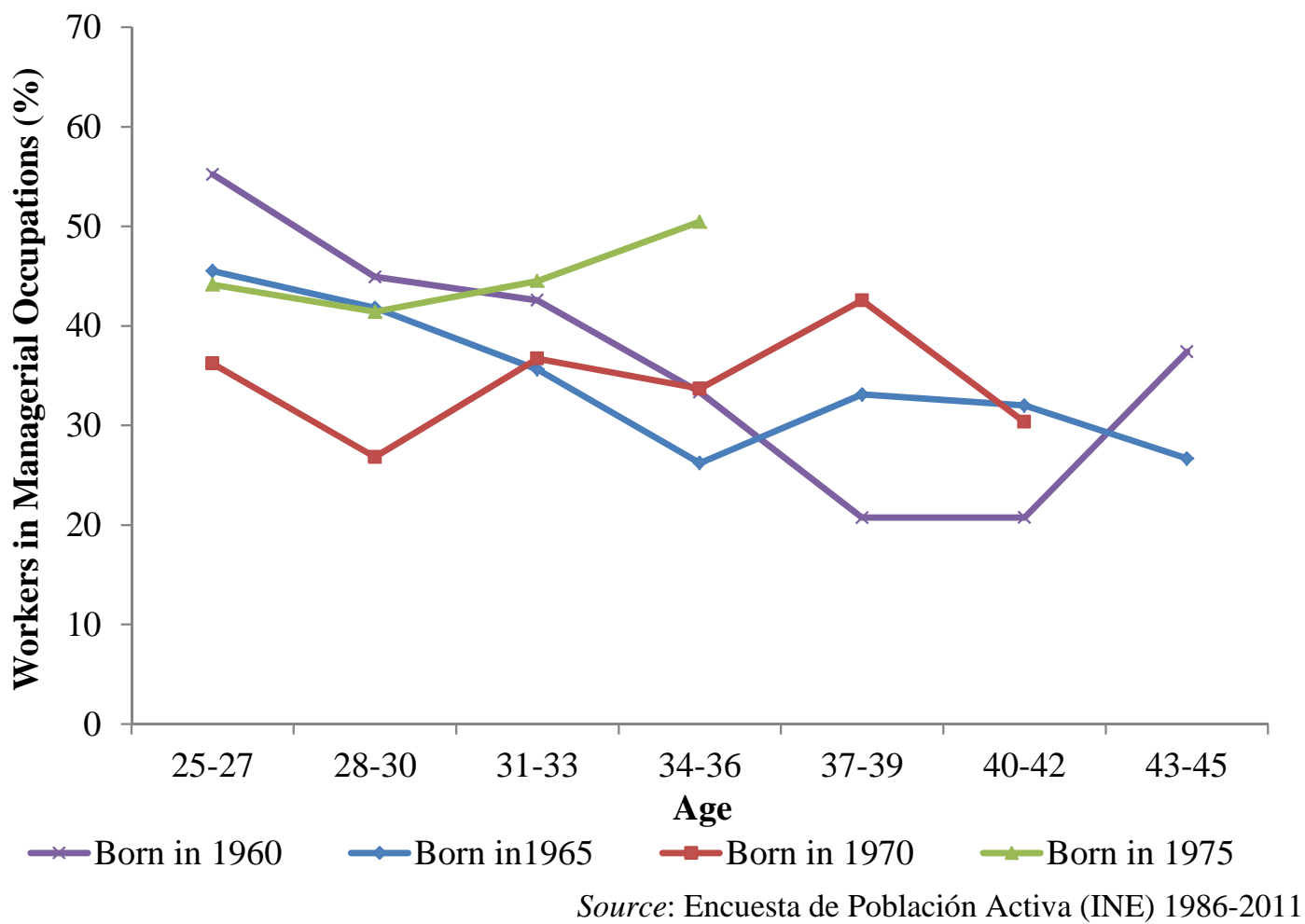


Table 1. Labor Market Statistics of College-Educated Men and Women Age 25-45 in Spain 1994-2008

\begin{tabular}{lcccccc}
\hline \hline & Employment Rates & Part-Time Rates & Managers incidence \\
& $\mathbf{1 9 9 4}$ & $\mathbf{2 0 0 8}$ & $\mathbf{1 9 9 4}$ & $\mathbf{2 0 0 8}$ & $\mathbf{1 9 9 4}$ & $\mathbf{2 0 0 8}$ \\
\hline 1. All Men & 93.12 & 91.82 & 2.31 & 1.84 & 6.85 & 3.14 \\
& $(25.34)$ & $(27.41)$ & $(15.03)$ & $(13.47)$ & $(25.30)$ & $(17.45)$ \\
2. All Women & 68.52 & 85.20 & 12.33 & 14.45 & 0.98 & 0.80 \\
& $(46.49)$ & $(35.52)$ & $(32.93)$ & $(35.18)$ & $(9.91)$ & $(8.93)$ \\
3. Men without children & 87.19 & 88.93 & 3.04 & 2.58 & 4.71 & 1,39 \\
& $(33.54)$ & $(31.38)$ & $(17.24)$ & $(15.86)$ & $(21.27)$ & $(11.74)$ \\
4. Men with children & 95.73 & 96.72 & 2.01 & 0.71 & 7.76 & 5.84 \\
& $(20.24)$ & $(17.88)$ & $(14.06)$ & $(8.38)$ & $(26.80)$ & $(23.48)$ \\
5. Women without children & 76.07 & 87.65 & 15.03 & 11.06 & 1.61 & 1.18 \\
& $(42.81)$ & $(32.91)$ & $(35.89)$ & $(31.38)$ & $(0.66)$ & $(10.84)$ \\
6. Women with children & 65.01 & 82.29 & 10.86 & 18.73 & 0.66 & 0.50 \\
& $(47.76)$ & $(38.19)$ & $(31.19)$ & $(39.04)$ & $(8.12)$ & $(7.05)$ \\
Gender Gap All (2-1) & -24.60 & -6.62 & 10.02 & 12.61 & -5.87 & -2.34 \\
Gender Gap no child (5-3) & -11.12 & -1.28 & 11.99 & 8.48 & -3.10 & -0.21 \\
Gender Gap children (6-4) & -30.72 & -14.43 & 8.85 & 18.02 & -7.10 & -5.34 \\
Family Gap Women (6-5) & -11.06 & -5.36 & -4.17 & 7.67 & -0.95 & -0.68 \\
\hline No. observations & 1033 & 3452 & 842 & 3027 & 842 & 3027 \\
\hline \hline
\end{tabular}

Notes: Standard deviations in parenthesis. Rates are computed using individuals' weights.

Source: Household Panels Phogue 1994 and EU-Silk 2008.

Table 2. Log Mean Hourly Wages of College-Educated Men and Women Age 25-45 in Spain 1994-2008

\begin{tabular}{lcccccc}
\hline \hline & & \multicolumn{1}{c}{$\mathbf{1 9 9 4}$} & & & $\mathbf{2 0 0 8}$ & $\ldots \ldots \ldots$ \\
& All & $\begin{array}{c}\text { Without } \\
\text { children }\end{array}$ & $\begin{array}{c}\text { With } \\
\text { children }\end{array}$ & All & $\begin{array}{c}\text { Without } \\
\text { children }\end{array}$ & $\begin{array}{c}\text { With } \\
\text { children }\end{array}$ \\
\hline 1. Men & 1.987 & 1.819 & 2.056 & 2.445 & 2.353 & 2.591 \\
& $(0.678)$ & $(0.746)$ & $(0.636)$ & $(0.448)$ & $(0.418)$ & $(0.457)$ \\
2. Women & 1.923 & 1.926 & 1.921 & 2.334 & 2.237 & 2.459 \\
& $(0.696)$ & $(0.719)$ & $(0.685)$ & $(0.452)$ & $(0.444)$ & $(0.432)$ \\
Gender Gap (2-1) & -0.064 & 0.107 & -0.135 & -0.111 & -0.116 & -0.132 \\
\hline \hline
\end{tabular}

Source: Household Panels Phogue 1994 and EU-Silk 2008. Note: Standard deviations in parenthesis. 
Table 3. Probability of Employment - Probit Estimation College-Educated Men/Women

\begin{tabular}{|c|c|c|c|c|c|c|c|}
\hline & \multicolumn{3}{|c|}{1994} & \multicolumn{4}{|c|}{2008} \\
\hline \multirow{3}{*}{ 1. Female } & {$[1]$} & {$[2]$} & [IV1] & [1] & {$[2]$} & [IV1] & [IV2] \\
\hline & $-0.101^{* *}$ & $-0.088^{*}$ & 0.048 & -0.012 & -0.015 & 0.019 & 0.019 \\
\hline & $(0.047)$ & $(0.047)$ & $(0.044)$ & $(0.017)$ & $(0.017)$ & $(0.019)$ & $(0.022)$ \\
\hline \multirow[t]{2}{*}{ 2. Any child } & $0.138^{* * *}$ & $0.098^{*}$ & 0.116 & $0.117^{* * *}$ & $0.073^{* *}$ & $0.081^{*}$ & 0.116 \\
\hline & $(0.046)$ & $(0.050)$ & $(0.082)$ & $(0.027)$ & $(0.028)$ & $(0.045)$ & $(0.069)$ \\
\hline $\begin{array}{l}\text { 3. Female*Any } \\
\text { child }\end{array}$ & $\begin{array}{c}- \\
0.214^{* * *} \\
(0.058)\end{array}$ & $\begin{array}{c}-0.192^{* * *} \\
(0.059)\end{array}$ & $\begin{array}{c}-0.221^{* *} \\
(0.088)\end{array}$ & $\begin{array}{c}- \\
0.161^{* * *} \\
(0.032)\end{array}$ & $\begin{array}{c}-0.162^{* * *} \\
(0.032)\end{array}$ & $\begin{array}{c}-0.257^{* * *} \\
(0.043)\end{array}$ & $\begin{array}{c}-0.242^{* * *} \\
(0.049)\end{array}$ \\
\hline
\end{tabular}

\section{Adjusted Family Gap}

For Women $(2+3)$

$-0.106^{*}$

$-0.176^{* * *}-0.126^{*}$

$(0.062)$

(0.034)

(0.063)

For Men (2)

0.116

$0.081^{*}$

0.116

$(0.082)$

(0.045)

(0.069)

\section{Adjusted Gender Gaps}

Women any child versus Men any child $(1+3)$

$$
\begin{gathered}
-0.173^{* * *} \\
(0.026) \\
0.048
\end{gathered}
$$

Childless Women versus Childless Men

(0.036)

(0.033)

(1)

(0.044)

0.019

0.019

Control variables

$\begin{array}{cc}\text { No } & \text { Yes } \\ 1033 & 1033 \\ 0.1262 & 0.1484\end{array}$

Yes

(0.019)

(0.022)

Observations

$\begin{array}{cc}10.08 & 11.24 \\ {[-0.025]} & {[-0.028]}\end{array}$

No

Yes

Yes

Yes

Pseudo $R^{2}$

1033

$3452 \quad 3452$

3452

3452

Family contribution to the gender gap (\%)

0.0339

0.0671

0.0795

0.0692

Notes: Standard errors in parenthesis; ${ }^{* * *} \mathrm{p}<0.01,{ }^{* *} \mathrm{p}<0.05,{ }^{*} \mathrm{p}<0.1$. The set of control variables include age, presence of a working spouse/partner, other family income in the household and regional fixed effects. Individual sampling weights are used in the estimations. The presented coefficients are marginal effects from probit models. The computation of the family contribution to the overall gender gap follows the methodology of probit decomposition into coefficient effects developed by Yun (2003). Absolute contributions in brackets. 
Table 4. Probability of Working Part-Time versus Full-Time - College-Educated Men/Women

\begin{tabular}{lccccccc}
\hline \hline & & 1994 & & \multicolumn{4}{c}{2008} \\
1. Female & {$[1]$} & {$[2]$} & {$[I V 1]$} & {$[1]$} & {$[2]$} & {$[I V 1]$} & {$[$ [IV2] } \\
& $0.097^{* * *}$ & $0.106^{* * *}$ & $0.139^{* *}$ & $0.096^{* * *}$ & $0.089^{* * *}$ & $0.088^{* * *}$ & $0.097^{* * *}$ \\
2. Any child & $(0.035)$ & $(0.036)$ & $(0.060)$ & $(0.018)$ & $(0.017)$ & $(0.020)$ & $(0.025)$ \\
& -0.020 & -0.008 & 0.074 & $-0.067^{* *}$ & -0.045 & $-0.086^{* *}$ & -0.066 \\
3. Female*Any & $(0.034)$ & $(0.043)$ & $(0.096)$ & $(0.032)$ & $(0.029)$ & $(0.042)$ & $(0.068)$ \\
child & -0.003 & -0.012 & -0.060 & $0.112^{* * *}$ & $0.111^{* * *}$ & $0.129^{* * *}$ & $0.106^{* *}$ \\
& $(0.042)$ & $(0.045)$ & $(0.080)$ & $(0.035)$ & $(0.034)$ & $(0.047)$ & $(0.051)$
\end{tabular}

\section{Adjusted Family Gap}

For Women $(2+3)$

0.014

$0.042^{*} \quad 0.040$

(0.065)

(0.027)

(0.054)

For Men (2)

0.074

$-0.086^{* *}-0.066$

(0.096)

(0.042)

(0.068)

\section{Adjusted Gender Gaps}

Women any child versus Men any child

$0.079^{* *}$

$0.217^{* * *} 0.203^{* * *}$

$(1+3)$

(0.033)

(0.036)

Childless Women versus Childless Men

$0.139^{* *}$

$0.088^{* * *}$

(0.039)

(1)

(0.060)

(0.020)

$0.097^{* * *}$

Control variables

$\begin{array}{cc}\text { No } & \text { Yes } \\ 841 & 750 \\ 0.0898 & 0.1079\end{array}$

Yes

Yes

(0.025)

Observations

0.0898

0.1079

$$
750
$$

No

Yes

Yes

Pseudo $R^{2}$

$\begin{array}{cc}-5.43 & 4.10 \\ {[-0.005]} & {[0.004]}\end{array}$

$3027 \quad 3027$

3027

3027

$\begin{array}{lll}0.1087 & 0.1220 & 0.1502\end{array}$

0.1386

0.1339

Family contribution

to the gender gap

(\%)

10.79

8.58

7.60

Notes: Standard errors in parenthesis; $* * * \mathrm{p}<0.01,{ }^{* *} \mathrm{p}<0.05,{ }^{*} \mathrm{p}<0.1$. The set of control variables include age, presence of a working spouse/partner, other family income in the household and regional fixed effects. Individual sampling weights are used in the estimations. The presented coefficients are marginal effects from probit models. Absolute contributions in the last raw in brackets. 
Table 5. Log Wage Regressions College-Educated Men/Women - Dependent Variable: Log Hourly Wages

\begin{tabular}{|c|c|c|c|c|c|c|c|c|}
\hline \multirow{4}{*}{ Female } & \multicolumn{4}{|c|}{1994} & \multicolumn{4}{|c|}{2008} \\
\hline & {$[1]$} & [2] & [3] & [IV1] & [1] & [2] & [3] & [IV1] \\
\hline & 0.085 & 0.066 & 0.039 & 0.118 & $-0.115^{* * *}$ & $-0.092^{* * *}$ & $-0.066^{* * *}$ & $-0.064^{* * *}$ \\
\hline & $(0.063)$ & $(0.061)$ & $(0.052)$ & $(0.084)$ & $(0.022)$ & $(0.021)$ & $(0.019)$ & $(0.022)$ \\
\hline \multirow[t]{2}{*}{ Any Child } & $0.189^{* * *}$ & 0.010 & 0.055 & 0.083 & $0.116^{* * *}$ & $0.099^{* * *}$ & $0.056^{* *}$ & $0.228^{* * *}$ \\
\hline & $(0.050)$ & $(0.052)$ & $(0.044)$ & $(0.084)$ & $(0.029)$ & $(0.026)$ & $(0.025)$ & $(0.033)$ \\
\hline \multirow[t]{2}{*}{ Female*Any Child } & $-0.209^{* * *}$ & $-0,138^{* *}$ & $-0.136^{* * *}$ & $-0.232^{* * *}$ & -0.016 & -0.004 & -0.005 & -0.042 \\
\hline & $(0.076)$ & $(0.069)$ & $(0.062)$ & $(0.097)$ & $(0.034)$ & $(0.031)$ & $(0.028)$ & $(0.038)$ \\
\hline \multirow[t]{2}{*}{ Age } & & $0.089^{* *}$ & 0.049 & 0.058 & & $0.054^{* *}$ & $0.056^{* * *}$ & $0.044^{* * *}$ \\
\hline & & $(0.043)$ & $(0.040)$ & $(0.043)$ & & $(0.020)$ & $(0.017)$ & $(0.017)$ \\
\hline \multirow[t]{2}{*}{ Age squared } & & -0.001 & -0.001 & -0.001 & & -0.001 & -0.001 & -0.001 \\
\hline & & $(0.001)$ & $(0.001)$ & $(0.001)$ & & $(0.001)$ & $(0.001)$ & $(0.001)$ \\
\hline \multirow[t]{2}{*}{ Tenure } & & $0.009^{* *}$ & $0.013^{* * *}$ & $0.013^{* * *}$ & & 0.002 & $0.006^{* * *}$ & $0.006^{* * *}$ \\
\hline & & $(0.004)$ & $(0.003)$ & $(0.003)$ & & $(0.002)$ & $(0.002)$ & $(0.002)$ \\
\hline \multirow[t]{2}{*}{ Part-Time } & & $0.145^{* * *}$ & $0.045^{*}$ & 0.035 & & $-0.151^{* * *}$ & $-0.117^{* * *}$ & $-0.126^{* * *}$ \\
\hline & & $(0.068)$ & $(0.063)$ & $(0.063)$ & & $(0.030)$ & $(0.026)$ & $(0.026)$ \\
\hline Industry dummies & No & Yes & Yes & Yes & No & Yes & Yes & Yes \\
\hline Regional dummies & No & Yes & Yes & Yes & No & Yes & Yes & Yes \\
\hline Occupations & No & No & Yes & Yes & No & No & Yes & Yes \\
\hline Observations & 828 & 802 & 796 & 793 & 2602 & 2537 & 2533 & 2533 \\
\hline$R^{2}$ & 0.021 & 0.1955 & 0.3917 & 0.3960 & 0.0795 & 0.3132 & 0.4533 & 0.4539 \\
\hline $\begin{array}{l}\text { Family } \\
\text { contribution } \\
\text { to the gender gap }\end{array}$ & & & $\begin{array}{c}85.50 \\
{[-0.055]}\end{array}$ & $\begin{array}{c}100 \\
{[-0.101]}\end{array}$ & & & $\begin{array}{c}-16.51 \\
{[0.018]}\end{array}$ & $\begin{array}{c}0 \\
{[0.065]}\end{array}$ \\
\hline
\end{tabular}

Notes: Standard errors in parentheses; $* * * \mathrm{p}<0.01, * * \mathrm{p}<0.05, * \mathrm{p}<0.1$. The set of control variables include age, age squared, years of tenure in the actual job, industry dummies, occupations- 4 digits of the ISCO classification of occupations, and regional fixed effects. Individual sampling weights are used in the estimations. Absolute contributions in brackets. 